\section{THE MYTHS OF ENVIRONMENT: MAGICAL PLACES IN PORTUGAL AND THEIR RELATION WITH GEOMORPHOLOGY \\ Teresa Azevêdo[1], Elisaluete Nunes[2]}

${ }^{(1,2)}$ Centro de Geologia, Departamento de Geologia, Faculdade de Ciências de Lisboa, Ed. C6 - 4º Piso. Campo Grande. 1749016 Lisboa, Portugal.

e-mails: (1)terazeve@fc.ul.pt / (2)elisabete.nunes@fc.ul.pt

\section{Abstract:}

There are thousands of megalithic monuments dolmens, passage mounds, menhirs and cromlechs - in Portugal from which the best preserved occurred in the eastern part of the country, almost all built of granitic rocks and on granitic hills, but they can also be built in shales, sandstones and limestones. These pre historic monuments have since always been an enigma: their religious meanings, the rituals of early man, and the manner in which they enigmatically interacted with their surroundings.

The question is, what did these megalithic monuments represent in the lives of early man and what is their relationship to the landform morphology and lithology of the respective sites? How did rocks and landscapes condition the selection of these sites?

This paper tries to explain the distribution of some megalithic monuments and heritage features in Portugal as a function of various factors, including geology, lithology, and landform development.

After analysing the influence of the several geomorphological features on the choice of megalithic sites, we did not find any reason strong enough to explain it. Then another question was posed: which could be the real reasons for their choice? Radiesthesic methods can give a complete explanation for this even if the scientific community has not accepted them until today. This work tries to open a path for a new envisagement of science and for the bounding between science and parascience.

Key-words: Portugal, archaeology, geology, pre-historic monuments, landform morphology

\section{Introduction}

The places where pre-historic populations erected the first nucleus that later became defensive structures, villages and towns have always been essentially conditioned by the position of the settlement regards to the food sources and communication via (proximity of fluvial via) and by the topographic position allowing to catch sight of a probable enemy at a distance. In this case, Geology and Geomorphology play a fundamental role as these places often constitute reliefs, which are originated by the harder nature of rocks or are of tectonic origin. However, there are prehistoric monuments that were not conditioned by these factors and other explanations can be given.

The aims of this work are:

- to find the link between Meso/Neolithic occupation in Portugal and the natural environment (rocks, water, soils, flora, fauna, in summary, the landscape understood as a whole in permanent evolution);

- to understand why Alentejo, in east of Portugal, has the biggest density of megalithic monuments as it is a very flat and arid region even assuming that in that period the climate was less drier than today;

- to enrich the understanding of the present-day society through the know-how's relative to the longest period of humankind.

Portugal possesses some of the earliest examples of European Mesolithic and Neolithic structures like Menhirs and Passage mounds, dating back before 7,000 BC. In addition, it also contains a range of more recent structures including examples of Spiral rock-art, Stone circles, Ogham's script and even Cart-ruts (Strada's Real).

\section{Pre-historic occupation of Tagus River}

One of the oldest places of human occupation in Portugal is the Tagus alluvial plain, which has been occupied since the Lower Palaeolithic. The Tagus is the longest river $(1100 \mathrm{~km})$ in the Iberian Peninsula and its basin is the third largest one in this territory, draining a total area of $80629 \mathrm{~km}^{2}$. Particularly rich in lithic artefacts is the 
Middle Terrace Q3 in Almeirim region, where about 3000 pieces dated from the Pleistocene (Micoquian - 120,000 years) were found in only $20 \mathrm{~m}^{2}$.

In the Upper Mesolithic, but before the beginning of the megalithic culture, the population lived mainly on the banks of the Tagus River. The three Muge Shell Middens, are sites of incalculable value to the knowledge of the everyday life of the populations that about 6000 years inhabited these banks ( 8000 years cal BP to prior to 6000 years cal BP) [1]. A primary reason for occupying the Muge Valley must have been the abundance of estuarine molluscan found in salt marshes. However, environmental conditions changed as an increase in aridity was accompanied by diminishing of tidal influence and higher salinity levels. These changes made Muge valley unattractive for Mesolithic populations that preferred other areas such as the Tagus or Sado estuaries, Beiras (Central Portugal) or the adjacent uplands of Upper and Central Alentejo, almost uninhabited at the time. In the Upper Alentejo, there are very early dates associated with Megalithic monuments.

\subsection{MEGALITHIC MONUMENTS - DOLMENS,}

\section{(ANTAS), MENHIRS, AND CROMLECHS}

The thousands of megaliths in Portugal are dispersed all over the country but they concentrate specially in the referred regions where there are several "complexes" as: Muge, Évora, Estremoz, Reguengos de Monsaraz, Castelo de Vide, Orca, etc.

They are almost all built of granitic rocks and stand preferentially on granitic sites, but they can also be built in shale, greywacke, sandstone, and limestone. Many of them were converted into Christian temples by the Christianisation of the territory, as the antas of Pavia and Arronches that are now in the middle of the villages and converted into chapels. From the several Cromlechs, Menhirs and Passage mounds, the Cromlech of Almendres, the passage-mound of Anta do Zambujeiro and the Menhir do Outeiro, a huge granite bulk reaching to about $6 \mathrm{~m}$ in height, are the most impressive.

Therefore, what did these megalithic monuments represent to early man and how do they relate to the paleoenvironmental and paleoecological characteristics of the respective sites? We tried to answer some of these questions by attempting to find the influence of some geomorphological factors.

\subsection{INFLUENCE OF LITHOLOGY AND RELIEF}

\section{2.a) distribution of dolmenic monuments in} relation with lithology and relief

Even if there is a perfect coincidence between granite and quartz diorite outcrops and the occurrence of megaliths (for example, in the Monsaraz region), there are, however, many built with other Hercinian materials, like shales. In the hydrographic basin of Sever river, Alto Alentejo, the concentration of monuments defines the boundary between granites and shales. On the other hand, in the upper part of the region the concentration of dolmens is related to the Tagus Valley occupation, in sedimentary rocks, and with the big rock art complex of Foz Côa [1].

Alentejo is an extensive province of Portugal occupying about $1 / 3$ of the country. From the geomorphological point of view, it is a peneplain, a wavy surface with a median altitude of $240 \mathrm{~m}$, dipping between 0 and $5 \%$, only interrupted by some reliefs of tectonic or residual origin and dominated by granites and shales of the Hercinic Massif. It is now a very arid region even if crossed by three important hydrographic basins: Tagus, Sado and Guadiana. It is wheat cultivated and only cork oak and olive trees can survive.

The "Anta Grande do Zambujeiro" near Évora, has the largest stones of any passage mound in all Portugal, and possibly one of the largest in all Europe. The granitic stones extend over $7 \mathrm{~m}$ above ground and the whole construction was covered by a big mound. Research supports the idea that there is a relationship between passage mounds and the astronomical orientation of their passages [2]. Nowadays people still celebrate the spring equinox with a Celtic Festival (Trás-os-Montes).

2.2.b) Distribution of chromlechs and menhirs in 


\section{relation with lithology and relief}

The countryside around Évora has a huge variety of cromlechs. This region of Portugal offers some of the biggest and the best sites in Iberia. Recent discoveries of astronomical alignments between sites support the idea that the Évora region was a very important one in pre-history.

Near Évora, the Cromlech of Almendres is the most impressive. This ancient sacred place has nowadays 95 menhirs and represents the biggest assemblage of structured menhirs of the Iberian Peninsula and one of the most interesting in Europe $(60 \mathrm{~m} \mathrm{~W}-\mathrm{E}$ and $30 \mathrm{~m} \mathrm{~N}$ $\mathrm{S}, 400 \mathrm{~m}$ altitude, dipping $11 \%$ ). Its axis is oriented $\mathrm{E}$ W. It suffered different stages of construction over the Neolithic and there are reliefs and engravings in more than one dozen of its monoliths. It is believed that it functioned as an astronomic observatory aiming to fix the calendar as an element to unify the Cosmo - Nature rhythm and human rhythm of life.

On one of the menhirs, 13 wise-snake symbols the staff - are engraved. The Almendres menhir, $1.5 \mathrm{~km}$ away, is aligned with the cromlech in the solstice axis. It seems to have been a cultual place with strong magicalsymbolic power and it reflects the particular economic, social and ideological transformations that occurred from the Middle Neolithic to the Iron Age, that is, from the end of the 6 th to the beginning of the $3 \mathrm{rd}$ millennium.

Another question is, why did people of the Meso/ Neolithic build more than one thousand megaliths in this flat and inhospitable region?

Contrasting with the flat morphology of the Alentejo, the Beira region shows a very irregular morphology with high mountains (the highest Portuguese mountain, Serra da Estrela, is located there) as the result of the Hercinian orogenic movements which created horsts and grabens and a dense grid of faults. A very dense arboreal vegetation of pines, oaks, and chestnut trees cover the region.

In this entire region, over 400 megalithic monuments are described in literature. In particular, the Orca Complex is one of the most interesting and with several dolmens and other structures that combine together to form the "Circuito Pré-Histórico de Fiais".

In the Algarve region, South of Portugal, almost all the monuments are built in limestone or in greywacke according with the rock source of Mesozoic materials $[1,3]$.

\section{The influence of environment}

After analysing the influence of geomorphologic factors, we concluded that megalithic monuments appear not to be influenced by the environment as they are localized indistinctively in regions of vigorous relief or in peneplains, besides rivers or far from them, in vegetated regions or in arid ones. Lithologic nature of rocks is also not fundamental: there are monuments built in granite (the most abundant), gneiss, shale, greywacke, sandstone, or limestone, depending on the local rock source.

Hundreds of archaeologists tried, over the last centuries, to answer the previous questions. The reading and searching of dozens of scientific and parascientific works about megalithism allow us to consider that none of the given archaeological explanations can satisfy, even the archaeologists. They only agree in that they served for funerary and ceremony rituals and that they could have astronomic aims. Regarding these inconclusive results, we looked for other reasons for the selection of the implantation sites of the megalithic monuments.

\section{Hartman and Curry Grids}

In the literature on this theme, there is a complete theory that answers these questions based on the existence of an energetic grid that covers the whole earth, discovered by two German doctors - Hans Hartman and Manfred Curry - based in the occurrence of Telluric Currents. According to them, the Earth is an electromagnetic body with its own electromagnetic grid pattern. The most important is called the First Global Grid, or Hartmann Grid or Net, comprised of 
parallel energy waves rising vertically from the ground, described as alternatively positive and negative, forming a grid across the earths surface with a distance of circa 2 meters in the N-S direction and 2.5 meters in the E-W direction (the distances differ from area to area). Curry lines (Curry Grid), are understood to be circa 3 meters apart (with variations), diagonally to the poles, E-W. Curry and Hartman consider the existence of the earth radiation a theoretical geophysical phenomenon and describe it as a mystic force field that supposedly covers the earth at regular intervals and may be detected and flawlessly measurable through non-scientific equipment used by radiesthesists.

Menhirs are known to stand always in the crossing (knots) of two or more Hartman and Curry lines (as well as underground water) just as dolmens are always in their centre (figure 1). The first are points of strong emission of energy that can be felt by humans and animals, while the latter are complete neutral places and, therefore, of serenity and tranquillity. This characteristic explains their choice for funerary places.

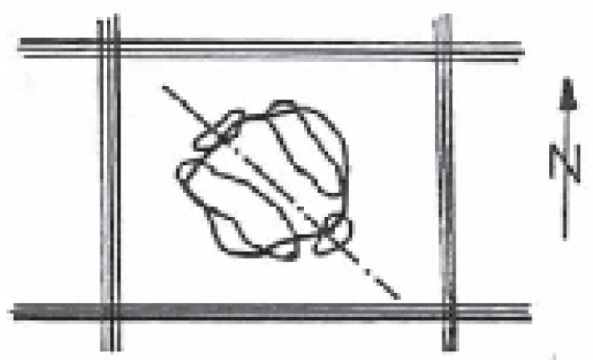

Figure 1 - An example of a dolmen inside the Hartman Grid [4].

Radiesthesists state that telluric energies are negatively polarised and that the cosmic flow is positive. The negative energy flows along the stone and escapes to the sky attracted by the cosmic "plus". This ascendant

blow induces acceleration, like a vortex of cosmic positive flow around the menhir, which attracts the negatively polarised telluric current, probably through the channel opened by the ascendant energy. Both energies, one coming from the sky and the other from the earth, connect to create a third energy that will surpass the addition of the other two. The cosmic flow carries the vital energy and the water transmits the memory of the energy and life of the earth to the telluric current. Water memory has been proved through the work of the Japanese scientist Masaru Emoto [5] and his conferences all over the world. Therefore, explanations that account to Hartmann and Curry Currents can satisfy all the observed phenomena and give logical and useful purposes to the colossal work represented by megalithic culture.

\section{Methodology \\ 5.1 Magnetometer measures}

In a first approach to measure this energy with scientific equipment, we started by searching for magnetic anomalies near the menhirs and we selected the main menhirs of two cromlechs, both in granite: Vale Maria do Meio and Portela de Mogos some $6 \mathrm{~km}$ distant from each other. Four ground magnetic stations were carried out in these two areas, from about $35 \mathrm{~m}$ to $5 \mathrm{~m}$ distance from the menhirs and just beside them at each $5 \mathrm{~m}$. The surveys were carried out using a proton magnetometer of $0.02 \mathrm{nT}$ sensitivity and the magnetic measurements were corrected for diurnal variations. The corrected values of the total magnetic field are in figure 2.

In the first site - Vale Maria do Meio - the resulting pattern of the magnetic field indicates an increase of the values in the proximity of the menhir. This behavior is not observed in the second site (Portela de Mogos) where more stable values are noted. Nevertheless, the observed small variability $(<30 \mathrm{nT})$ of the magnetic field can be due to the geological variability. These results are not conclusive once they are quite homogeneous and the detected anomalies can be attributed to the granite itself. 


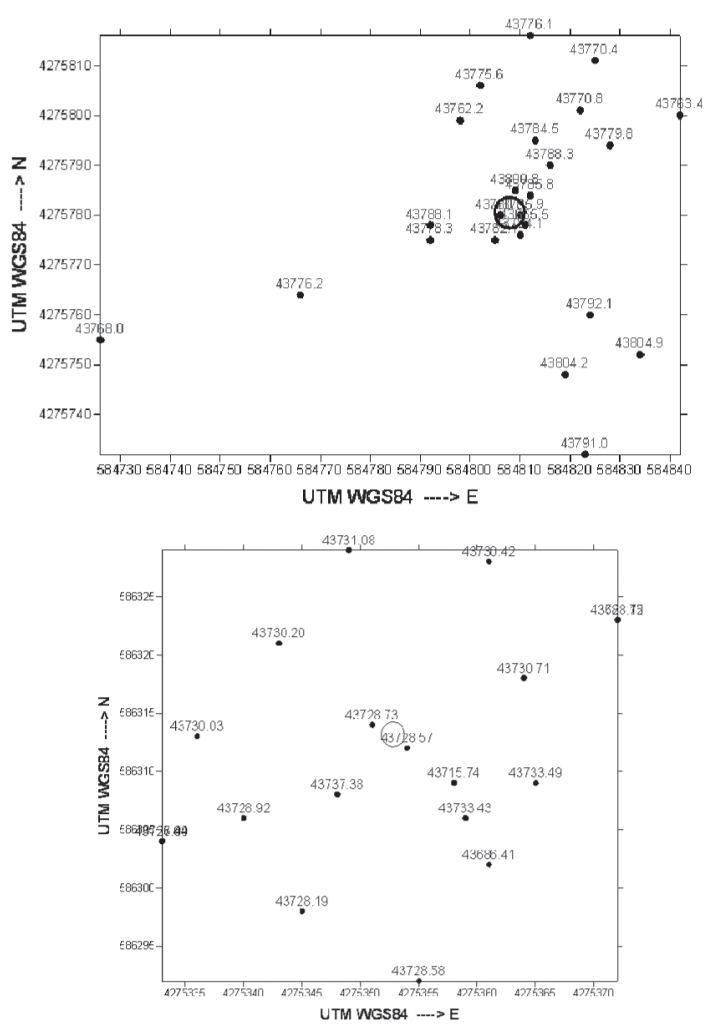

Figure 2 - Magnetometer measures at Vale Maria do Meio and Portela de Mogos.

\subsection{Radiesthesic measures}

Due to these also inconclusive results and deciding to try the same experiments now with the simpler and universally used radiesthesic equipment, like a Pendle and the universal abacus of Bovis. We began by measuring the energy of several objects (like trees, flowers, chairs, stones, etc) in order to have a background value to compare with those of the megaliths, according to the works of Bovis, Bonvin, [6], and Le Cossec, [4]. The obtained values fell between 6000 and 7500 Bovis Units (B.U.). Then we measured the previous menhirs and the respective values went up to the 18000 B.U., values, which are usually, attributed to sacred places [7]; [4]; [6]. Later, we carried out the same experiments in the King's Chamber in the Giza Pyramid and also in the Temple of Hathor, in Egypt. Both places gave values higher than 20000 B.U.

\section{Interpretation}

It is clear for us that there is a special energy in some spots all over the world and that it can be measured by non-scientific equipment. Although this has been only a first approach to the subject, our purpose is to add our research to that of other scientists that are also trying to understand what kind of energy we deal with [8]. It can result from variations in the electromagnetic field or other anomalies but it may be that there is presently no adequate equipment to reach/measure it due to its exceedingly different frequency from the usual events. It will be necessary to develop special measuring equipments.

This subject has to do with the bounding between science and parascience or with the epistemology of science: What is it true in science? Is it the real, visible, and already known phenomena that everybody can observe and prove or it is also those ones that science does not yet know? If unknown phenomena are not interesting for scientists will it ever be discovered? Should we not study an unknown subject only because it is not yet corroborated and measured?

\section{Conclusions}

Analysing the geomorphological and geological characteristics of the regions where the thousands of Megaliths are implanted in Portugal, we did not find any strong enough reason to explain the selection for these sites. In a first attempt to prove that there is a special energy in those points, that can explain their selection, we tried to measure it with scientific equipment by using a magnetometer.

Due to the inconclusive results of this first experiment and our conviction that there must be a way to read it, our current and future work concerns the following points:

- use other scientific equipment, such as oscilloscopes, resistivity meters, voltmeters, to compare with the values that are only known by the radiestesy teams, even if they are supposedly undetectable by common scientific 
instruments;

- develop an adequate instrument if the previous ones are not able to detect the energy values;

-prove to the scientific community that unknown and invisible phenomena can be studied and brought to the light of science;

- change the concept that the Planetary Energy Grid Theory falls under the heading of pseudoscience and let it be accepted by the scientific community.

Its time to admit that there are still many unknown events and that we must find other paths to envisage their origin!

\section{Acknowledgements}

We thank our colleague Fernando Monteiro of the Department of Physics of the FCUL for helping with the measurements of the magnetic anomalies.

\section{References}

1 - J.L. Cardoso, Pré-história de Portugal, Ed. Verbo, Lisboa, 2002, p. 456.

2 - J.F. Santucci, G.Thury-Bouvet, A. Ottavi \& K. El Hadi, Astronomical Orientations of Neolithic Tombs in Monte Revincu, in A. Aiello, J.F. Santucci (ed.), Congrès International Environnement et identité en Méditerranée, (2005), 8 p.

3 - J.L. Cardoso, J.C., Caninas, A., Gradim, A.N. Joaquim, Menires do Alto Algarve Oriental: Lavajo I e Lavajo II (Alcoutim), Ver. Portuguesa de Arqueologia, Vol. 5, No. 2., (2002), p. 99-133.

4 - G. Le Cossec, Le Souffle du Menhir, Ed. Dervy, Paris, 1998, p. 166.

5 - M. Emoto, The Message from Water, Hado Kyoiku Sha Publishers, Japan, 1999, p. 145.

6 - J. Bonvin, Mégalithes - Lieux d'énergie, Ed. Mosaique, France, 1995, p. 283.

7 - B. Mertz, Hauts Lieux Cosmo-Telluriques, Georg Editeur, France, 1990, p 199.

8 - H-D. Langer, A first consistent physical model of radiestesy?, The Sixteenth Seminar of BDA, Druskininkai, Lithuania, 2008, p.75-86. 